\title{
Enhancing Local Education for Sustainable Development Through Learning Cycle Instructional Model
}

\author{
Hussein Zanaty, Toshio Eisaka \\ Kitami Institute of Technology, Kitami, Japan
}

\begin{abstract}
Improving education achievement through the use of more integrated digital equipment is becoming an essential part of social development. However, the benefit of implementing the equipment in longitudinal learning approach is not fully explored in education for sustainable development in local societies. This study aims to develop learning and skills of local teachers and children based on a sustainable learning cycle instructional model. The learning cycle of this study is divided in three main phases: forming, informing, and reforming (FIR). The FIR is to promote 6E conceptual learning elements (i.e., experimentation, exploration, explication, elaboration, evaluation, and extension) in local education for sustainable development. The expected result of the implementation of the FIR-6E learning cycle model is to show better results in developing self-regulation and motivation skills than those who are taught using both the conventional constructional style and the 5E (i.e., engagement, exploration, explaination, elaboration, and evaluation) instructional model.
\end{abstract}

Keywords: education for sustainable development, active learning, learning cycle, self-regulation, motivation

\section{Introduction}

In the realm of education for sustainable development, the United Nations Educational, Scientific and Cultural Organization (UNESCO) (2005) investigated the major problems in education: (a) the lack number of teachers and qualification; and (b) the lack of appropriate sustainable instructional tools, which focus on competencies of integrating educational technology into teaching. According to the International Board of Standards for Training, Performance, and Instruction (IBSTPI) assumptions, the instructional design is an effective tool that aimed at the transfer of training and improved individual and organizational performance indicators (Richey, Fields, Foxon, Roberts, Spannaus, \& Spector, 2001). In the current climate of education, a significant body of research has called attention to the need of enhancing students' meaningful and active environment through integrating instructional technology into learning. This integrated technology can transform learning environments to address higher order of thinking skills, teach advanced concepts (Christensen, 2002; Guzman \& Nussbaum, 2009), and develop self-regulation skills (Zimmerman, 2000; Järvelä, Järvnoja, \& Veermans, 2008; Pintrich, 2000; Dignath, Buettner, \& Langfeldt, 2008) in a longitudinal learning environment. Within this setting, the way in which students engage in learning activities and how to integrate instructional model in enhancing learning and skills are being challenged. In terms of learning activities, teachers strive to provide a meaningful learning which focuses on developing students' critical 
thinking and self-regulation skills. Another critical issue is how to design an effective learning model using integrated technology to assist teachers' lesson plan and authentic materials. To support teachers with effective lesson plans and curriculum development demands in their traditional one-way superficial learning, they may need an interactive learning cycle instructional system to enhance students' critical thinking and self-regulation skills (Zimmerman, 2000) and improve learning and knowledge retention for sustainable development. Therefore, this study focuses on incorporating the FIR learning cycle (i.e., forming, informing, and reforming) $6 \mathrm{E}$ instructional model (i.e., experimentation, exploration, explication, elaboration, evaluation, and extension) into active learning pedagogy in order to develop local education for sustainable development.

\section{The Conventional Learning Cycle}

The learning cycle is the process whereby knowledge is created through the transformation of experience (Kolb, 1984). Students need to relate new ideas to their experience and place new ideas into a framework for understanding (Bransford, Brown, \& Cocking, 2001). Thus, the learning cycle is a critical learning process in improving students' self-regulation approach with better retention of concepts, improved reasoning ability, and superior processing skills than would be the case with traditional instructional approaches (e.g., Karplus \& Their, 1967; Abraham \& Renner, 1986; Beeth \& Hewson, 1999).

Many versions of the learning cycle introduced in scientific studies with concepts ranging in number from three (Karplus \& Their, 1967) to five (Bybee, 1997) to seven (Eisenkraft, 2003). The common 5E (i.e., engagement, exploration, explaination, elaboration, and evaluation) model introduces unique instructional elements of understanding and actively building new knowledge from prior knowledge. It incorporates the three core learning cycle phases, explore, introduce, and apply/extend, while adding two conceptual changes, engage and evaluate. The $5 \mathrm{E}$ model mainly focuses on developing students' formulation of a better understanding of scientific and technology knowledge within peers and their environment. Some studies found that students taught via the learning cycle scored higher on a test than students taught with the traditional style (Gerber, Cavallo, \& Marek, 2001). Figure 1 shows the 5E model and its conceptual elements relationship.

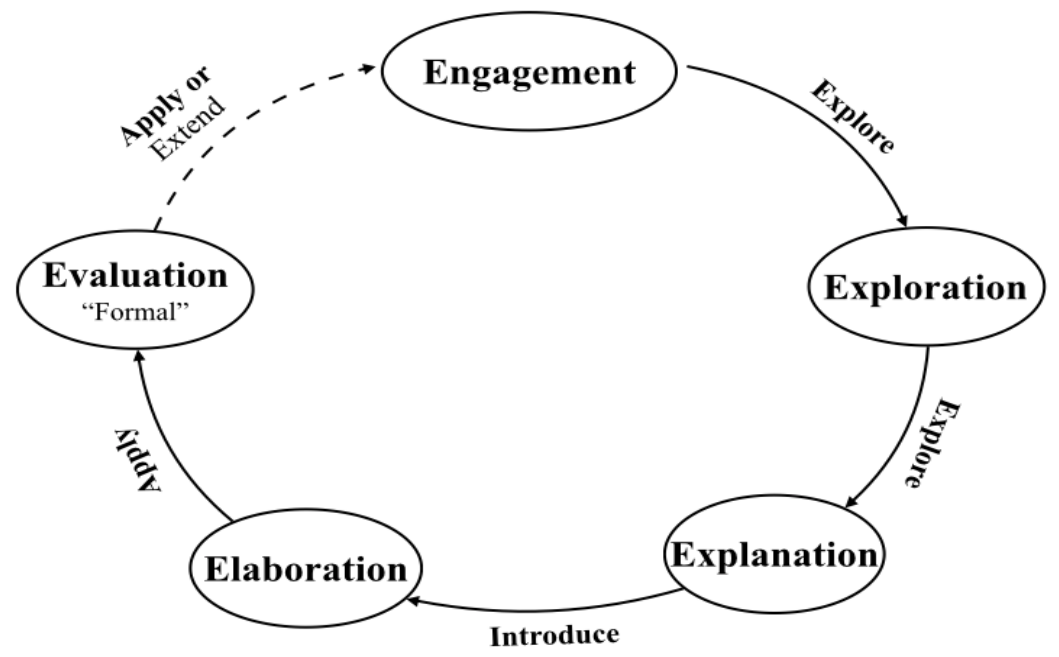

Figure 1. The 5E conceptual elements.

The 5E model introduces the formal evaluation as the main reflection on students' overall achievement. However, the $5 \mathrm{E}$ model is based on formal evaluation and reflection, which implemented at the end of the 
whole process. This may lead to decrease in students' motivation. Therefore, involving students in sustainable multiple experiences in the longitudinal learning approach may improve students' long-term self-achievement and attitudes. In order to develop long-term outcome of students' self-regulation and motivation skills, teachers need to engage their students in social tasks and teach the students how to use them productively (Joyce \& Weil, 1996) in a longitudinal learning environment.

\section{The Proposed FIR-6E Learning Cycle}

The proposed learning cycle phases of FIR is designed to promote the $6 \mathrm{E}$ conceptual elements: experimentation, exploration, explication, elaboration, evaluation, and extension. The FIR-6E instructional model assigned to provide the opportunity to maintain three learning aspects: 1 . Forming the self-experimentation and self-reflection; 2. Informing self-achievement in a longitudinal learning environment; and 3. Reforming the dissemination of students' information to the community in sustainable local and international environments.

Cognitive scientists insist that students need to relate new ideas to their experience and place new ideas into a framework for understanding (Bransford et al., 2001). Also, in order to contribute these ideas in a meaningful and sustainable learning environment, the authors introduce the FIR phases and its 6E conceptual elements in where students can develop their self-regulation skills as peer-educators. The FIR phases were designed to increase students' productivity in education for sustainable development. This means that students are to participate in a variety of active roles in an integrated learning process in the way to develop their self-regulation skills in creating digital learning materials with the support of teachers' facilitation. Thus, the FIR phases are supported by qualitative and quantitative assessments of self-achievement informal evaluation right after each phase in order to maintain the validity and reliability of the methodology. The expected impacts of the instructional design of this study would provide self-regulated students an opportunity to organize their set goals in order to achieve more appropriate outcomes goals; provide students with an opportunity to develop self-observation and self-experimentation in a longitudinal learning environment; and provide an opportunity for the dissemination of students' information to the community.

Figure 2 shows the FIR phases and its 6 E conceptual elements relationship.

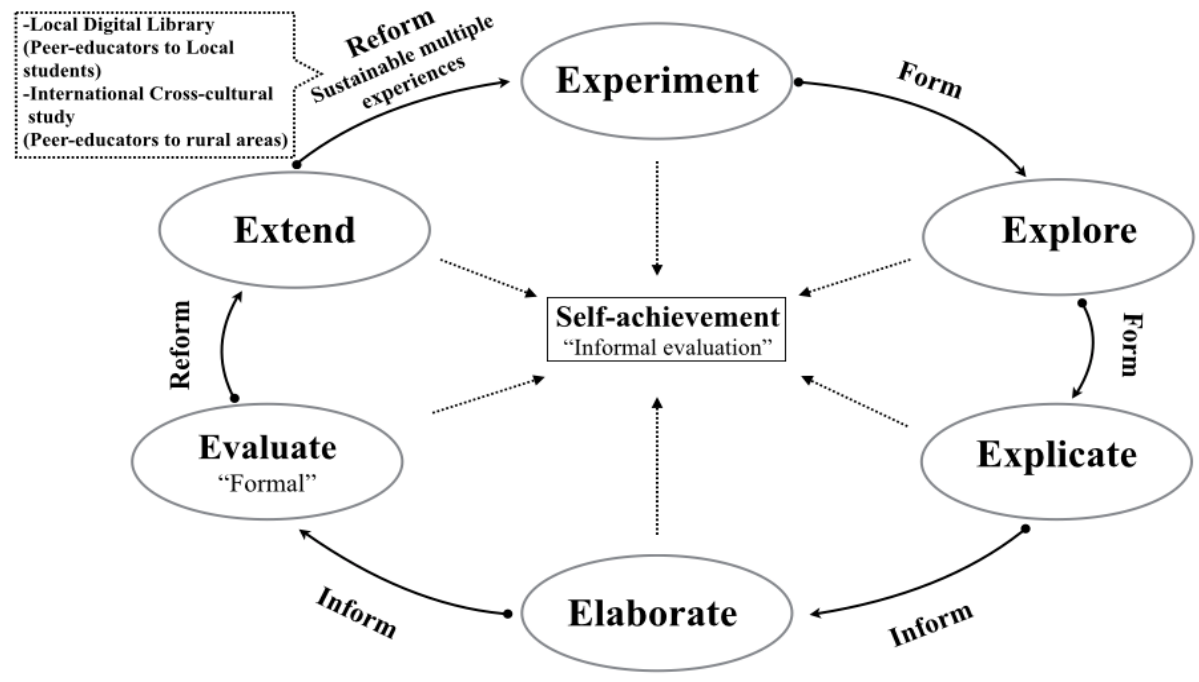

Figure 2. The FIR-6E conceptual elements for sustainable development. 
The above system illustrates the relationships and prescribed actions between conceptual elements. The FIR-6E system provided both descriptive and prescriptive processes. As a descriptive process, the system shows relationships and illustrates what happens within an interactive environment in a variety of roles and responsibilities. As a prescriptive process, the system shows a variety of procedures, assignment methods, and a guide of self-regulated activity through self-achievement assessments.

\section{The Forming Phase: Learning and Training}

The forming phase illustrates two learning approaches, which are input and output, as well as two learning concepts, experimentation and exploration, in an attempt to learn and train students on how to access self-regulated learning materials. Tomlinson (2010) emphasized the effective input in the learning environment. He stated that in order to acquire the ability to use the language effectively, the learners need a lot of experience of the language being used in a variety of different ways for a variety of purposes. They need to be able to understand enough of this input to gain positive access to it and it needs to be meaningful to them. With this in mind, this phase introduces a variety of different learning ways, which allow students the opportunity to turn their one-way learning style to a more active learning approach through the necessary resources. If we have necessary resources (Web, digital tools, and content expertise), then we can design and deliver an instructional model appropriate for educators (Taylor \& Henert, 2008).

Consistent with the intent of the forming phase, our initial activity is intended to elicit elementary students' prior knowledge about the learning environment. The activities designed in this phase include forming groups and roles, solving problems, designing a group task scenario, and applying what they learnt to develop their skills. The process is supported with assessment of student attitudes and performance sheets. At the end of each period of the process, students are asked to record their achievements through informal evaluation sheet and process guide sheet. The process guide sheet was designed to record students' self-regulation progress that will enable them to maintain their motivation and their life-long learning attitude (Boekaerts \& Corno, 2005). Zimmerman (1986) also emphasized how self-regulation skills have significant impact on students' academic achievement. Zimmerman (1986) stated that "Self-regulated learners are behaviorally, motivationally, and meta-cognitively active participants in their own learning process" (as cited in Mchael, David, Jeroen, \& Marcy, 2008, p. 121).

In addition, the forming phase developed two concepts of instruction:

1. Experimentation, which provides students with the opportunity in experimenting in self-regulated pedagogies, connecting their past and present learning experiences and opportunities to learn independently and from one another;

2. Exploration, which provides students with an opportunity to investigate and develop their contexts through integrated digital learning tools including personal computers, digital cameras, tablets, and editing applications.

By exposing these concepts, students will be able to engage in an effortful and mindful experience with a variety of active roles, such as innovators, self-developers, problem-solvers, co-thinkers, challengers, and meaning-makers that led them to contribute in an on-going learning environment.

\section{The Informing Phase: Intervention and Active Learning Environment}

The informing phase is critical for maintaining an active learning environment following the initial activities of this study. The activities in this phase focus on developing two learning approaches, outputs and 
short-term outcomes, and two learning concepts, explanation and elaboration, in an attempt to maintain an active and a meaningful learning process. In order to achieve that, we incorporate the self-regulated learning with productive learning in a group work. The activity intends to shift student attitudes from that of being passive learners to peer-educators.

The tasks include delivering and accessing each group's digital content, designing group scenario, and creating an illustrated guide according to each student's responsibility. The teacher's role is to facilitate and observe the gradual achievement. Consistent with the intent of the informing phase of the FIR-6E instructional model, the activity intends to elicit students' prior experiences and skills, demonstrate students' current understanding, and select the appropriate form to be used in sustainable development experience. Taylor and Hernet (2008) also stated that if we design and deliver this instructional module, then our educators would access it, learn about, and develop skills in logical models. At the end of each period of this phase, the students are asked to record their task achievement through student evaluation sheet and process guide sheet. The next stage will elaborate how the assigned interactive activities will assist in developing meaningful outcomes in a longitudinal learning environment.

The interactive activities focused on the collective and shared activity of group members in a real-world situation that maintained motivation. According to Jackson, Mckenzie, and Hobfoll (2000), motivation is created and maintained through the collective, interactive, and even shared activity of group members. Kolb in his 1984 paper titled "Experiential Learning: Experience as the Source of Learning and Development" referred to an old aphorism accredited to Confucius around 450 B.C.: "Tell me, and I will forget. Show me, and I may remember. Involve me, and I will understand" (as cited in Spector, Merrill, Van Merrienboer, \& Driscoll, 2008).

In addition, the informing phase develops two concepts of instruction:

1. Explication, which allows students to compare methods and achievement of other group in an interactive learning environment, and to be able to present their method in easy features in the last phase case study. Here the role of the homeroom teacher is to facilitate the process and group presentations;

2. Elaboration, which provides students with the opportunity to develop their skills in logic models and implement their experience in a sustainable learning experience.

By exposing these concepts, students will be able to expand their learning approach and their ability of English communication and cross-cultural awareness.

\section{The Reforming Phase: Longitudinal Learning Cycle}

To apply what students have learnt, the reforming phase is planned to reflect on a new sustainable learning experience as peer-educators. It also provides a summative assessment for teachers and students to evaluate their interaction. The activities in this phase focus on the longitudinal learning cycle and the reflections on the impacts of the FIR-6E instructional model on students' attitudes. The reforming phase illustrates two learning approaches, which are outcome and impact, as well as two learning concepts, evaluation and extension, in an attempt to reflect and create a new learning situation effectively. In this phase, we incorporate the productive learning with the learning cycle process in a group work learning style. This phase allows students to reflect their applied skills and integrate these skills into real-world activities (Merrill, 2002).

In addition, the reforming phase developed two concepts of instruction:

1. Evaluation, which allows students to exchange feedback with an international partner, learn new methods, and improve conceptual pedagogy; 
2. Extension, which provides students with the opportunity to reengage in a new sustainable learning cycle.

Gradually, students' motivation will be increased by implementing a new experimental process. At the end of this phase, students will be able to conduct four effective experiential learning elements: (a) concrete experience; (b) observation and reflection; (c) formation of abstract concepts; and (d) testing in new situations (Kolb, 1984). By exposing these concepts, students will able to reflect and challenge themselves in a new learning situation at their own pace and disseminate their information to the community in a new sustainable learning development.

Finally, the FIR phases promote the following sub-achievements:

1. Improving students' ability from understanding materials (Sutherland \& Bonwell, 1996) to develop and integrate their own self-regulated learning materials;

2. Improving students' engagement in activities from cooperative learning (D. W. Johnson, R. T. Johnson, \& Smith, 1991) to peer-educators;

3. The FIR-6E instructional model plays a significant role as a teaching guide for elementary school teachers to gradually improve their students' conceptual understanding (Charles, Lasry, Whittaker, \& Trudeau, 2009) up to a longitudinal self-developer and disseminate students' experience into a new sustainable learning development.

\section{E Conceptual Elements}

The meaningful environment orientation effectuated a shift from materials to be presented in an instructional system to students' goal-oriented and self-regulated process with the instructional design system (Cooper, 1993). At present, there is an emerging focus on using K-12 students in studies using digital learning equipment. The present studies show higher level of students' motivation by the self-regulated elements of digital learning environments (Foster, 2008). As such, we need to implement an effective instructional learning system to be used in education for sustainable development at local schools. Therefore, we designed the FIR-6E model as a sustainable learning instructional system for the 5th grade elementary students in Japan to enhance a meaningful learning approach.

\section{The FIR-6E Conceptual Elements}

Experimentation. During this element process, students experiment a variety of digital equipment and editing softs. Students are to develop their basic skills to integrate digital equipment in a self-regulated process and understand how to create a cross-cultural DVD/digital contents. Teachers provide training and facilitate the progression of all tasks. Teachers create a folder for storing and evaluating the target cross-cultural DVD/digital contents. Tasks are designed in small group work. For informal evaluation, the process is evaluated by self-achievement card.

Exploration. This element is connected to the initial element process through group tasks. Students work in groups and develop their digital contents; create their action and timeline plan; create illustrated scenario with individual role; and make predictions, develop hypotheses, collect data, and draw conclusions through the self-created scenario. Teachers facilitate the process, observe interaction, and scaffold. For informal evaluation, the process is evaluated by self-achievement card and step-by-step action card.

Explication. This element is connected to the exploration process through providing students with the opportunity to explicate their methods, findings, and discoveries. Students have the opportunity to explicate 
how they implemented their digital equipment in detail to other groups. They select one digital equipment and editing software to develop a cross-cultural DVD. Teachers allow opportunities to develop ideas and concepts. Also, the teacher's role is to follow groups' action plan and self-achievement evaluation process. For informal evaluation, the process is evaluated by self-achievement card and step-by-step action card.

Elaboration. Based on the self-created action plan and illustrated scenario in the previous process, groups merge methods and digital equipment in creating the DVD contents. Students use past and present experiences in new interactive learning experience, and exchange DVD with international partners. The target DVD contents are to teach some sort of the Japanese traditional games, language, and sports. Teachers facilitate the process and observe students' interaction. For informal evaluation, the process is evaluated by self-achievement card and step-by-step action card.

Evaluation. Students work on experiment reflection, receive intrinsic feedback from local learners or international partners, understand the impact on their work, and develop more critical thinking and self-regulation skills through a new learning cycle process to be introduced to local learners or in sustainable experience. The students' role transforms from active learners to peer-educators. Teachers provide feedback and assist in new learning cycle process. For informal evaluation, the process is evaluated by self-achievement card, step-by-step action card, and teachers' observation.

Extension. In order to transform the peer-educators' new learning interest into a longitudinal learning environment, students develop new learning cycle process with more self-efficacy and self-regulated skills. Students contribute their past and present experiences in a sustainable learning case study. Teachers facilitate the process and observe students' motivation and interaction. For informal evaluation, the process is evaluated by self-achievement card, step-by-step action card, and overall interviews.

\section{Assessments}

The FIR-6E supported with qualitative and quantitative assessments and multiple methods. Assessments were designed to explore students' transfer of learning and to verify the implementation of FIR phases as a case of $6 \mathrm{E}$. The use of multiple methods, or methodological triangulation (Ashatu, 2009), would help to increase credibility of the FIR-6E instructional process. In order to maintain the validity and reliability of the FIR-6E learning cycle model, self-achievement informal evaluation is conducted in: (a) students' learning performance card; (b) self-achievement step-by-step card; (c) teachers' questionnaire; and (d) interviews.

The purpose of students' learning performance card is to visualize group behavior and performance in terms of central tendency and dispersion (Brown, 2006). While the purpose of students' self-achievement card is to help students manage and evaluate their task-centered, activation, demonstration, application, and integration (Merrill, 2000) through the assigned periods of the experiment.

\section{Discussion and Conclusion}

The primary purpose of this research study is to develop a sustainable learning model in local education and to gather initial data on its $6 \mathrm{E}$ conceptual elements. The expected results of implementing the FIR-6E in both local and international studies predict improvement in students' learning and skills through the integrated technology equipment. The study promotes three characteristics of the FIR-6E instructional model, including: 1. Whole meaningful tasks are seen as the driving force for learning; 2. Developing the learner-centered in the way to act as co-responsible for a process of competence development; and 3. It provides a renewed interest in 
learning approach through the benefit of integrating technology in education for sustainable development. The experimental group who will be exposed to the FIR-6E could develop their self-regulated skills, such as problem-solving, goal-based scenario, higher critical thinking, and active peer-educator approach through the dissemination of their information to the community.

The proposed FIR-6E instructional model does not aim to promote the technology equipment but how to integrate the digital equipment to promote learning in sustainable development in local area. The FIR-6E instructional model is not to belittle the impact of the common $5 \mathrm{E}$ model but to promote a longitudinal learning model to enhance local learners society.

The FIR-6E will provide a useful learning guide in order to form a strategy, inform their knowledge, and perform their creativity in a meaningful experience. The following are among the advantages that the model will develop:

(a) Gradual progress in the learning approaches and the significant transformation from knowledge-receiver to educator;

(b) Gradual progress in learning skills, such as strategy-making and community-developing;

(c) Gradual progress in the interactive learning style through communication, self-engagement, and innovative activities;

(d) Gradual progress in conceptual and cognitive learning outcomes through positive learning environment and developing learning concepts for sustainable learning development.

\section{Overall Principles for Promoting the FIR-6E}

The principles for promoting the FIR-6E are based on the study of Merrill (2000). The implementation of the FIR-6E model promotes some approaches for facilitating effective, efficient, and engaging instruction. Table 1 shows the instruction principles, promotion, and its rationales.

Table 1

Instruction Principles, Promotion, and Its Rationales

\begin{tabular}{|l|l|l|}
\hline Principle & Promotion & Rationale \\
\hline Task-centered & Learners undertake a progression of all tasks & To develop students' self-engagement \\
\hline Activation & Learners implemented self-regulation skills & $\begin{array}{l}\text { To develop conceptual understanding and increase } \\
\text { motivation in learning activities }\end{array}$ \\
\hline Demonstration & Learners used a variety of methods & $\begin{array}{l}\text { To develop self-efficacy, such as reducing anxiety } \\
\text { and improving attitudes }\end{array}$ \\
\hline Application & Learners shared an active learning environment & To develop pairs and group learning \\
\hline Integration & Learners integrate their new learning situation & To develop meaningful learning environment \\
\hline
\end{tabular}

\section{Future Implementation}

1. The FIR-6E should be implemented in local and international case study in education for sustainable development;

2. The use of the FIR-6E should be extended into academic institutions;

3. The FIR-6E instructional model should be promoted to agencies like UNESCO and should be used more widely to promote important issues in the field of education.

Finally, the FIR-6E model would provide opportunity to learners to act as peer-educators, gain confidence about creating a change in their learning environment, and experiment critical role contributing education for sustainable development. 


\section{References}

Abraham, M. R., \& Renner, J. W. (1986). The sequence of learning cycle activities in high school chemistry. Journal of Research in Science Teaching, 23(2), 121-143.

Ashatu, H. (2009). The use of triangulation in social sciences research: Can qualitative and quantitative methods be combined? Journal of Comparative Social Work, 1, 1-12.

Beeth, M. E., \& Hewson, P. W. (1999). Learning goals in exemplary science teacher's practice. Science Education, 83(6), 738-760.

Boekaerts, M., \& Corno, L. (2005). Self-regulation in the classroom: A perspective on assessment and intervention. Applied Psychology: An International Review, 54(2), 199-231.

Bransford, J. D., Brown, A. L., \& Cocking, R. R. (2001). How people learn: Brain, mind, experience, and school. Washington, D.C.: National Academies Press.

Brown, J. D. (2006). Understanding research in second language learning: Teacher's guide to statistics and research design. Cambridge, U.K.: Cambridge University Press.

Bybee, R. W. (1997). Achieving scientific literacy: From purposes to practices. Portsmouth, N.H.: Heinemann.

Charles, E. S., Lasry, N., Whittaker, C., \& Trudeau, J. (2009). Technology supported collaboration and learning: How do we build learning environments to build communities and conceptual knowledge? (PAREA report). Montreal, Q.C.: Dawson College.

Christensen, R. (2002). Effects of technology integration education on the attitudes of teachers and students. Journal of Research on Technology in Education, 34(4), 412-433.

Cooper, J. D. (1993). Literacy: Helping children construct meaning (2nd ed.). Boston, M.A.: Houghton Mifflin Company.

Dignath, C., Buettner, G., \& Langfeldt, H. P. (2008). How can primary school students learn self-regulated learning strategies most effectively? A meta-analysis on self-regulation training programmes. Educational Research Review, 3, 101-129.

Eisenkraft, A. (2003). Expanding the 5E model. The Science Teacher, 70(6), 56-59.

Foster, A. (2008). Games and motivation to learn science: Personal identity, applicability, relevance and meaningfulness. Journal of Interactive Learning Research, 19(4), 597-614.

Gerber, B. L., Cavallo, A. M. L., \& Marek, E. A. (2001). Relationship among informal learning environments, teaching procedures, and scientific reasoning abilities. International Journal of Science Education, 23(5), 535-549.

Guzman, A., \& Nussbaum, M. (2009). Teaching competencies for technology integration in the classroom. Journal of Computer Assisted Learning, 25, 453-469.

Hannafin, M. J., Hill, J. R., Land, S. M., \& Lee, E. (2014). Student-centered, open learning environments: Research, theory, and practice. In J. M. Spector, M. D. Merrill, J. Van Merrienboer, \& M. P. Driscoll (Eds.), Handbook of research on educational communications and technology (5th ed., pp. 641-651). London, U.K.: Routledge.

Jackson, T., McKenzie, J., \& Hobfoll, S. E. (2000). Communal aspects of self-regulation. In M. Boekaerts, P. R. Pintrich, \& M. Zeidner (Eds.), Handbook of self-regulation (pp. 275-300). San Diego, C.A.: Academic Press.

Järvelä, S., Järvenoja, H., \& Veermans, M. (2008). Understanding the dynamics of motivation in socially shared learning. International Journal of Educational Research, 47, 122-135.

Johnson, D. W., Johnson, R. T., \& Smith, K. A. (1991). Active learning: Cooperation in the college classroom. Edina, M.N.: Interaction Book Company.

Joyce, B. R., \& Weil, M. (1996). Models of teaching (5th ed.). Boston, M.A.: Allyn and Bacon.

Karplus, R., \& Thier, H. D. (1967). A new look at elementary school science. Chicago, I.L.: Rand McNally.

Kolb, D. A. (1984). Experiential learning: Experience as the source of learning and development. Englewood Cliffs, N.J.: Prentice-Hall.

Mchael, J. S., David, M. M., Jeroen, V. M., \& Marcy, P. D. (Eds.). (2008). Handbook of research on educational communication and technology (Chapter 10, p. 121). New York, N.Y.: Lawerence Erlbaum.

Merrill, M. D. (2000). Knowledge objects and mental models. In D. A. Wiley (Ed.), The instructional use of learning objects. Washington, D.C.: Association for Educational Communications and Technology. Retrieved from http://reusability.org/read

Merrill, M. D. (2002). First principles of instruction. Educational Technology Research and Development, 50(3), 43-59.

Pintrich P. R. (2000). The role of goal orientation in self-regulated learning. In M. Boekaerts, P. R. Pintrich, \& M. Zeidner (Eds.), Handbook of self-regulation (pp. 451-502). San Diego, C.A.: Academic Press.

Pintrich, P. R., \& Schunk, D. H. (2002). Motivation in education: Theory, research, and applications (2nd ed.). Upper Saddle, N.J.: Prentice-Hall, Inc.. 
Richey, R. C., Fields, D. C., Foxon, M., Roberts, R. C., Spannaus, T., \& Spector, J. M. (2001). Instructional design competencies: The standards (3rd ed.). Syracuse, N.Y.: ERIC Clearinghouse on Information and Technology.

Spector, J. M. Merrill, M. D., Van Merrienboer, J., \& Driscoll, M. P. (2008). Handbook of research on educational communications and technology (3rd ed.). Mahwah, N.J.: Lawrence Erlbaum.

Sutherland, T. E., \& Bonwell, C. C. (1996). Using active learning in college classes: A range of options for faculty. In New directions for teaching and learning (No. 67). San Francisco, C.A.: Jossey-Bass.

Taylor, P. E., \& Henert, E. (2008). Developing a logic model: Teaching and training guide. Madison, W.I.: University of Wisconsin-Extension, Cooperative Extension, Program Development and Evaluation. Retrieved from http://www. uwex. edu/ces/pdande

Tomlinson, B. (2010). Principles of effective materials development. In N. Harwood (Ed.), English language teaching materials: Theory and practice (pp. 81-108). Cambridge, U.K.: Cambridge University Press.

United Nations Educational, Scientific and Cultural Organization (UNESCO). (2005). The UN decade of education for sustainable development (DSED 2005-2014): The DESD at a glance. Retrieved from http://unesdoc.unesco.org/images/0014/ 001416/141629e.pdf

Zimmerman, B. J. (1986). Development of self-regulated academic learning: Which are the key sub-processes? Contemporary Educational Psychology, 16, 307-313.

Zimmerman, B. J. (2000). Attaining self-regulation: A social cognitive perspective. In M. Boekaerts, P. R. Pintrich, \& M. Zeidner (Eds.), Handbook of self-regulation (pp. 13-41). San Diego, C.A.: Academic Press. 